\title{
Neurovascular abnormalities in brain disorders: highlights with angiogenesis and magnetic resonance imaging studies
}

\author{
Chiao-Chi V Chen ${ }^{1 \dagger}$, Yu-Chen Chen ${ }^{2 \dagger}$, Han-Yun Hsiao ${ }^{1,2}$, Chen Chang ${ }^{1 *}$ and Yijuang Chern ${ }^{1 *}$
}

\begin{abstract}
The coupling between neuronal activity and vascular responses is controlled by the neurovascular unit (NVU), which comprises multiple cell types. Many different types of dysfunction in these cells may impair the proper control of vascular responses by the NVU. Magnetic resonance imaging, which is the most powerful tool available to investigate neurovascular structures or functions, will be discussed in the present article in relation to its applications and discoveries. Because aberrant angiogenesis and vascular remodeling have been increasingly reported as being implicated in brain pathogenesis, this review article will refer to this hallmark event when suitable.
\end{abstract}

\section{Review}

Neurovascular abnormalities in brain disorders

The brain consumes one fifth of the body's energy and nutrients. The cerebrovascular system plays a key role in supporting the brain by providing oxygen and nutrients to the brain. Any abnormalities occurring in the cerebral microvasculature may affect the integrity of brain functioning. This relationship is best appreciated based on the concept of the neurovascular unit (NVU), which comprises multiple cell types, including neurons, vascular smooth muscle cells, endothelial cells, astrocytes, microglia, and pericytes [1] (Figure 1). Various types of dysfunction in these cells may impair the proper control of vascular responses by the NVU. For example, aberrant neuronal activity, abnormal calcium wave frequency in astrocytes, pathogenic proliferation of endothelial cells, or degeneration of vascular smooth muscle cells might affect the control of vascular responses in the brain [2-7].

Abnormal neurovascular alterations involve either structural or functional modifications of the cerebromicrovascular system. Structurally, increased tortuosity of the vasculature, increased thickness or permeability of the vessel walls, altered vessel density and size, and even

\footnotetext{
* Correspondence: bmcchen@ibms.sinica.edu.tw;

bmychern@ibms.sinica.edu.tw

${ }^{\dagger}$ Equal contributors

${ }^{1}$ Institute of Biomedical Sciences, Academic Sinica, Taipei 11529, Taiwan

Full list of author information is available at the end of the article
}

hemorrhage are possible changes in the neurovasculature. Neurodegenerative diseases that have been associated with structural abnormalities of the neurovasculature include Alzheimer's disease (AD), Huntington's disease (HD), and multiple sclerosis (MS). AD, as the most widespread dementia in the elderly, is linked to microvascular pathogenesis [8,9]. In $\mathrm{AD}$ transgenic mouse models, the notorious amyloid- $\beta$ aggregates are sometimes found surrounding aberrant neurovasculature. Changes in the blood vessel walls, in the permeability of the blood-brain barrier (BBB), and in the morphology of the vasculature have been reported. In HD, structural abnormalities of the neurovasculature are less appreciated, because of scarce evidence. Unlike what is observed in $\mathrm{AD}$, the integrity of the $\mathrm{BBB}$ is not impaired in HD, as several groups have observed [10,11]. However, narrowed vessels and increased vascularity have been found in postmortem HD brain tissues [12]. Indications of abnormal neurovasculature emerged very recently; however, the specific underpinnings are still being investigated [13]. MS is an elusive brain disorder that is associated with inflammation and demyelination. The venous system of the cerebral neurovasculature appears to be disrupted in MS [14]. These aberrations involve perivenular plaques and perivenular iron deposits. In some cases, these venous abnormalities can accompany local inflammation and demyelination. Other 

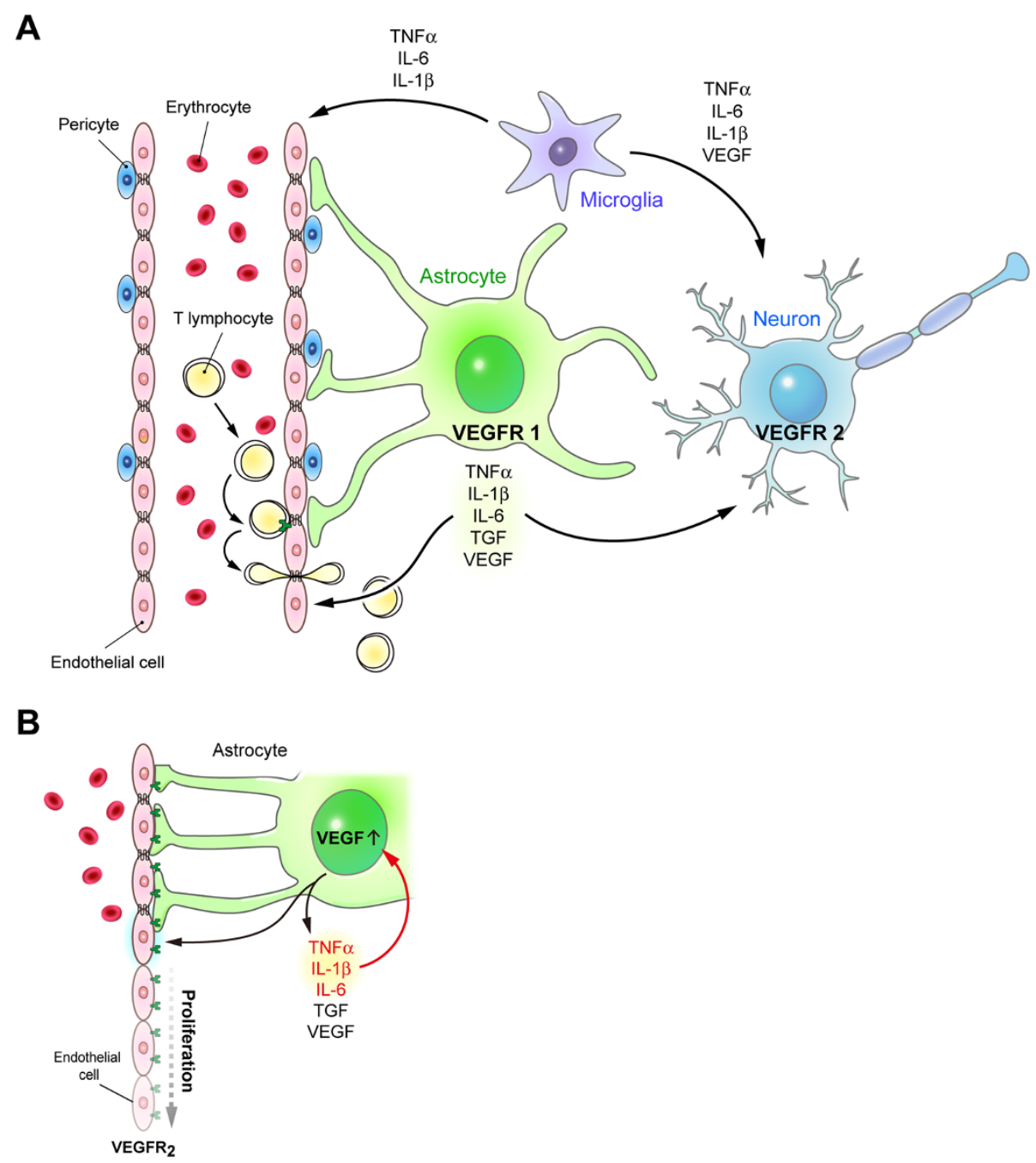

Figure 1 Illustration of the neurovascular unit (NVU) in the central nervous system. (A) The NVU comprises multiple cell types, including neurons, vascular smooth muscle cells, endothelial cells, astrocytes, microglia, and pericytes. Astrocytes and microglia release various factors (including TNF- $a$, IL-1 $\beta, I L-6$, and VEGF), which act on neurons and endothelial cells. (B) Enlarged illustration of the interaction between astrocytes and endothelial cells. Under pathological conditions, several inflammatory cytokines (TNF-a, IL-1 $\beta$, and IL-6) that are released by activated astrocytes may cause a positive feedback on the production of VEGF. These factors (TNF-a, IL-1ß, IL-6, and VEGF) may collectively induce the proliferation of endothelial cells and lead to neurovascular abnormalities in brain disorders.

neurovascular damages, such as BBB leakage, have also been reported in MS.

Functionally, the neurovascular abnormalities can be related to altered vascular perfusion in cerebral blood flow (CBF), cerebral blood volume (CBV), oxygen consumption and blood pressure $[15,16]$. Among these functional indicators, CBF changes are the most widely used. Abnormal blood flow has been commonly observed in brain disorders. For example, before the onset of cognitive impairment in patients with $\mathrm{AD}$, the blood flow in their brain is lower than that of control subjects [17,18]. Disturbance in the regulation of CBF was also reported in patients with HD [19-22]. Although area-specific disturbance of CBF was noted in the brains of HD patients, association between reduced $\mathrm{CBF}$ and regional atrophy was observed only in certain brain areas [19]. The regulatory role of $\mathrm{CBF}$ in neurodegenerative disorders is complex and requires further characterization.

Angiogenesis is a characteristic neurovascular aberration in brain disorders. It is a newly identified consequence of neurovascular remodeling triggered by the pathologies of brain disorders [9,15,23-29]. Angiogenesis features increased vascularity involving both structural and functional alterations within the neurovascular system. This hallmark event, although not yet completely evident in all brain disorders, might be a promising biomarker that can be used for the characterization of disease severity and progression in the future. 


\section{Angiogenesis in neurodegenerative diseases: molecular and cellular views}

Angiogenesis may involve the secretion of the vascular endothelial growth factor (VEGF). VEGF is a prominent molecule that acts directly on the proliferation of endothelial cells and may contribute to neovascularization or angiogenesis in brain pathologies. Marked overexpression of VEGF has been reported in brain disorders unrelated to tumors, such as AD [24], stroke, MS [25], and Parkinson's disease (PD) [23]. Reactive astrocytes are a major source of VEG overexpression. The activation of astrocytes in the scenario of brain disorders often implies the involvement of inflammatory reactions. The astrocytic VEGF-mediated neovascularization or angiogenesis in neuroinflammation is believed to be a reactive factor in many central nervous system disorders [30].

VEGF is the key molecule in the control of both vasculogenesis and angiogenesis. It is synthesized and released by neurons and astrocytes during early brain development and in the adult brain, respectively. The VEGF protein family consists of five different isoforms (VEGF-A, -B, -C, -D and -E). Among them, VEGF-A and VEGF-B are more abundant in the brain [31,32]. The functions of VEGF-A are closely associated with the angiogenesis process, whereas those of VEGF-B have been implicated in neuronal protection [33-35]. As a result of alternative splicing, five different VEGF-A isoforms (VEGF121, VEGF145, VEGF165, VEGF189, and VEGF206) have been identified that exhibit different affinities toward heparin and distinct abilities to regulate angiogenesis [34,36-38]. There are two receptors (flt-1, VEGF-R1; flk-1, VEGF-R2) for VEGF-A. VEGF-R2 is expressed mainly in endothelial cells and in some neurons [39]. The activation of VEGF-R2 in endothelial cells activates multiple pathways (including activation of the RAS/RAF/ERK $1 / 2$ and PI3K/AKT cascades, suppression of caspase 9, and stimulation of the Rac/ Rho pathway) to trigger proliferation, enhance survival, reorganize cytoskeletal structure, and stimulate migration $[40,41]$. In contrast, VEGF-R1 is expressed mostly in astrocytes and is important for astrocytic activation [39].

The expression of VEGF family members and their receptors was found to be upregulated in the brain after injury or trauma, which was associated with a subsequent enhancement of angiogenesis and increased neuronal availability of blood nutrients [42-46]. Nonetheless, it is important to note that high levels of VEGF-A in the brain can be pathogenic and lead to leakage of the BBB, production of proinflammatory cytokines (e.g., MIP-1 $\alpha$ ), promotion of leucocyte infiltration, and neuroinflammation $[47,48]$. Abnormal regulation of VEGF in astrocytes has been reported in several degenerative diseases.
For example, amyloid- $\beta$ (the causative agent in AD, [49]) was reported to stimulate the secretion of VEGF-A by astrocytes [50]. Similarly, a high level of VEGF-A and its receptor (VEGF-R1) was found in microglia of $A D$, which might contribute to angiogenesis and $\mathrm{BBB}$ leakage [51-53]. Consistent with these findings, enhanced microvascular density was reported in mice and patients with AD [24,54]. Impaired BBB function was also reported in AD mice (Tg2576; [54]). Elevated expression of VEGF was also reported in certain brain areas of patients with PD, which is another common neurodegenerative disease [55]. Such elevated brain VEGF levels might contribute to the increased angiogenesis found in the brains of PD patients and animal models [23,56,57]. Most intriguingly, the standard treatment for this disease (L-DOPA) was found to upregulate the expression of VEGF in astrocytes via the activation of the D1 dopamine receptor, which contributes to the development of a major side effect of L-dopa (dyskinesia, $[58,59])$.

Chronic inflammation is another important factor that might cause an abnormal neurovascular structure in the brain [60]. Many proinflammatory cytokines (such as IL-1 $\beta$, IL-6, TNF- $\alpha$, and the transforming growth factor $\beta 1$ (TGF- $\beta 1)$ ) were reported to enhance directly the proliferation of endothelial cells, thus triggering angiogenesis [61-63]. Elevated cytokines released by astrocytes accounted for not only neuroinflammation, but also angiogenesis in AD [61]. Via the NFkB- and/or HIF- $1 \alpha-$ dependent pathways, cytokines enhance the production and secretion of VEGF-A, which in turn triggers angiogenesis [50,64]. Conversely, TNF $\alpha$ reportedly stimulates its receptor on endothelial cells and enhances the response of endothelial cells to VEGF [65]. Because neuroinflammation is commonly observed in neurodegenerative diseases and disorders, an abnormal neurovascular structure associated with enhanced angiogenesis has been found in many brain disorders. In an $\mathrm{AD}$ mouse model triggered by the direct injection of amyloid- $\beta$ into the brain, the amyloid- $\beta$-induced production of TNF- $\alpha$ by microglia evoked significant angiogenesis and BBB leakage [66]. Similarly, the age-dependent enhancement of microglial activation was closely associated with vascular remodeling in the brain of a mouse model of HD (YAC128, [67]).

It is important to note that enhanced angiogenesis does not always result in increased CBF in the brain. In AD mice, large parenchymal amyloid plaques were associated with microvascular alterations and might case vascular degeneration, therefore disturbing CBF $[9,68,69]$. To evaluate the pathophysiological role of the NVU in each specific brain disorder, further characterization of the pathological response and regulation in the major cell types of the NVU is critical. 


\section{MRI as an important tool to explore neurovascular aberrations in vivo}

MRI is a powerful technique that allows both structural and functional characterization of the neurovasculature $[70,71]$. It identifies structural changes by direct visualizing the neurovasculature or measuring blood brain barrier permeability, the vessel size, and the vessel density. It also reveals functional alterations in the neurovasculature by measuring the $\mathrm{CBF}, \mathrm{CBV}$, oxygenation, and the oxygen consumption. The structural and functional information is essential to determine whether neurovascular aberrations such as angiogenesis, vascular remodeling, or loss of vascularity/vascular reactivity have occurred. The advantages of MRI well surpass that offered by histology or other imaging modality alone.

For structural characterization, the visualization of the neurovasculature is made possible by time-of-flight (TOF) magnetic resonance angiography (MRA) for larger vessels, or by microscopic MRA (mMRA) for the entire vasculature including arteries, arteriole, veins, and venule, or by venography for the venous system $[72,73]$. Vessel size and density can be characterized by steady state contrast - enhanced (SSCE) MRI [74]. The permeability of blood vessels can be measured by dynamic contrast-enhanced (DCE)-MRI [75].

For functional characterization, CBF can be measured by arterial-spin labeling (ASL) or dynamic susceptibility contrast (DSC)-MRI [76-78]. CBV can be measured by functional MRI with the use of contrast agents. The versatility of MRI allows a comprehensive characterization of both the structural and functional properties of the cerebral neurovascular system.

Among the abovementioned MR approaches, a cutting edge $3 \mathrm{D}$ mMRA technique based upon the $\triangle \mathrm{R} 2$ values was recently established [79]. 3D mMRA is unique and advantageous for its revelation of exquisite structures at the micron level with quantitative information of the vessel size, vessel density, and CBV. To reach the resolution and quality, this method entails the use of a contrast agent, iron oxide nanoparticles. The agent, after being injected intravenously, flows in the blood vessels including arteries, arterioles, veins, and venules with a half-life of 2-3 hours in the bloodstream. This consequently enables the visualization of the entire cerebral microvasculature.

Angiogenesis in brain disorders may be identified by MRI via versatile methods. Please refer to the following section of stroke because this disorder is most well established in this regard.

\section{Stroke}

In nontumor brain disorders, experimental stroke is the pathological condition that has been studied most widely using MRI [80]. DCE MRI identified BBB leakage at
3 days after ischemia in a rat stroke model called threevessel middle cerebral artery occlusion (MCAO) [27]. $\mathrm{BBB}$ leakage may be a combinational result from the initial ischemia-induced endothelial injury and the subsequence neurovascular remodeling. The alteration was not recovered, even at 21 days after the injury. In another rat stroke model induced by embolic focal cerebral ischemia, DCE-MRI indicated that treatment with neural progenitor cells caused the BBB leakage, which was observed at 2 weeks postischemia, returning to normal at 6 weeks [26].

Vascular remodeling involving angiogenesis is another key feature that is observed after ischemia [29]. As mentioned above, angiogenesis may involve both structural and functional changes of the neurovasculature; thus, it can be identified using versatile MRI methods. SSCEMRI offered structural evidence of angiogenesis during the postischemic stage [27]. Vessel density was significantly increased 2 weeks after ischemia and was sustained after 3 weeks in the MCAO model. Vessel size was largest within 3 days after ischemia, followed by normalization at later stages. Alternatively, the functional changes of increased CBF or CBV are also indicative of angiogenesis. Flow-sensitive alternating inversion recovery (FAIR) detected significantly elevated CBF in the infarct region as early as day 1 postischemia, and showed that it was sustained even at day 14 postischemia [28]. CBV measured using DSC-MRI was largest at day 7 postischemia, but was not significantly different from the baseline at days 1 and 14. For the purpose of demonstrating angiogenesis in stroke, 3D $\Delta R 2$ mMRA acquired from an MCAO rat at day 3 postischemia, a time point with active angiogenesis and vascular remodeling, is shown in Figure 2. The 3D $\Delta \mathrm{R} 2$ mMRA method proposed by Lin and colleagues [79] has the advantage to simultaneously characterize the structural and functional features. As shown in the Figure 2, even the small vessels from the remodeled neurovasculature can be revealed vividly by this approach [79].

\section{Alzheimer's disease}

AD is increasingly recognized as a neurovascular disease. There is growing evidence of neurovascular abnormalities in this disorder, as assessed using perfusion MRI. ASL and DSC are the most popular MR approaches in clinical AD research. ASL involves the magnetic labeling of arterial blood water as an endogenous tracer. The labeled blood water reduces total tissue magnetization, and the signal intensity of the slice of interest [81]. DSC, conversely, uses an exogenous gadolinium-based contrast agent as a tracer. Images are acquired rapidly as the contrast flows through the blood stream to establish the time-course data of signal changes. Functional indices, such as CBF and CBV, can be derived accordingly. 


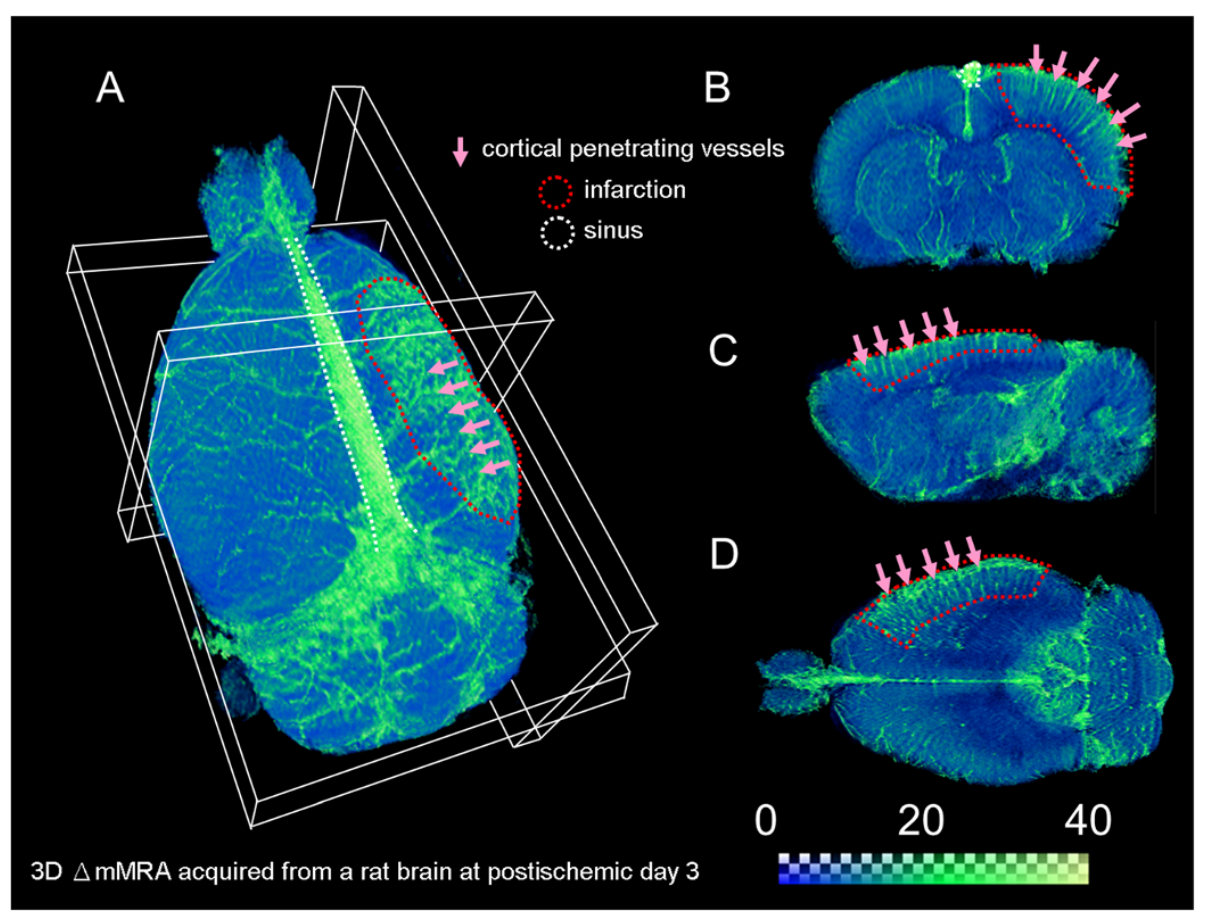

Figure 2 3D demonstration of the neurovascular remodeling and angiogenesis in experimental stroke. 3D $\triangle R 2$ mMRA was performed at day 3 after middle cerebral artery occlusion on a Sprague-Dawley rat. The ischemic region was located in the right cortex. The vessel signals are coded in the green color. (A) a 3D outlook, (B) an axial section, (C) a sagittal section, and (D) a horizontal section of the ischemic region. More cortical penetrating vessels are seen in the lesioned area, representing the hallmark event, angiogenesis.

A very detailed summary of ASL and DSC findings in $\mathrm{AD}$ patients is provided in the review authored by Chen et al. [82]. Briefly, using DSC, decreased CBF in widespread brain regions from AD patients was reported by several different groups, whereas increased CBF in the frontobasal regions has been found in patients with early AD and mild dementia. Similarly, ASL findings also indicate that $\mathrm{AD}$ is characterized by hypoperfusion in some areas and hyperperfusion in others. In particular, hyperperfusion is associated with an early progression of AD [81,83-86]. A possible explanation for this MRI finding during hyperperfusion in $\mathrm{AD}$ is angiogenesis, whereas the loss of vasculature is an explanation for the hypoperfusion; however, more direct evidence remains necessary.

There are also implications of structural alterations in the neurovasculature of AD. Ultra-high-field TOF-MRA revealed severe deficits in large- and medium-sized arteries in $\operatorname{Tg} 2576$ mice, which is a conventional AD mouse model. The aberrations were mainly observed in the middle cerebral artery and in the anterior communicating artery [87]. Another structural abnormality, BBB disruption, has been well documented in AD using microscopic examination and biochemical assays. However, in vivo demonstration of the damage is still lacking. Patients with mild cognitive impairments exhibited a tendency to have a leaky $\mathrm{BBB}$ in the hippocampus; however, the difference did not reach significance [88]. A clinical report indicated that DCE-MRI is likely sufficiently sensitive to reveal $\mathrm{BBB}$ leakage in $\mathrm{AD}$ if proper pharmacokinetic modeling is employed [89].

\section{Huntington's disease}

Emerging evidence indicates a role for neurovascular abnormalities in HD, although HD is typically viewed as a neurodegenerative disorder. A recent ASL study indicated that pre-HD individuals compared with controls showed hypoperfusion in medial and lateral prefrontal regions and hyperperfusion in the precuneus [22]. In addition, pre-HD with progression to symptom manifestation exhibited hypoperfusion in the putamen and hyperperfusion in the hippocampus. The measurement of relative CBV in R6/2 mice, which are a mainstay HD transgenic mouse model, revealed unusual increases in widespread regions, including the hippocampus, the cortex, the striatum, and the thalamus. The rCBV increases were associated with enhanced neuronal activity, and with decreases in glucose utilization [13]. The CBV increase observed in HD may be a result of neurovascular disruptions involving angiogenesis.

\section{Parkinson's disease}

$\mathrm{PD}$ is another refractory neurodegenerative disorder that afflicts the elderly and features dopaminergic 
dysfunctions of the basal ganglia. Investigations of the neurovascular abnormalities observed in the degenerated brain areas of PD patients remain inconclusive. DSC revealed higher perfusion in the more affected hemisphere of PD patients, and subcutaneous apomorphine administration normalized these changes [90]. However, ASL indicated preserved perfusion in the degenerated brain regions of PD patients compared with healthy controls, and decreased perfusion in other regions, including the posterior parieto-occipital cortex, precuneus and cuneus, and middle frontal gyrus [91]. Intriguingly, the neurovascular abnormalities become more salient if dopaminergic neurotransmission is engaged, i.e., CBV response of the lesioned striatum is significantly altered when dopaminergic agonists or antagonists are administered [92]. Moreover, in a rat PD model induced by 6-hydroxydopamine, the lesioned striatum exhibited a weakened $\mathrm{CBV}$ decrease in response to the nociceptive stimulus. This weakened CBV response occurred mainly in areas with dopaminergic denervation [93]. These studies indicate that the neurovascular abnormalities observed in PD are dependent on the neurotransmitter dopamine. This tight neurovascular coupling is unique, and again indicates the intimate relationship between the neural and vascular elements in brain functions.

\section{Conclusions}

Cerebral microvascular abnormalities are an important sign that may precede or concur with the major pathologies of brain disorders. The understanding of the importance of neurovascular remodeling and angiogenesis in brain disorders is still preliminary. Brain stroke and $\mathrm{AD}$ are probably the pathologies that have been most linked to neurovascular alterations and remodeling. Many other brain disorders, such as HD, PD, and MS are less appreciated in this regard. MRI, as a versatile and practical clinical diagnosis tool, is invaluable for identifying and characterizing the multiple aspects of the neurovascular aberrations of brain disorders, including angiogenesis. Recent MRI findings suggest that neurovascular alterations are likely to be present, even in the pathologies in which vascular disruptions were rarely considered. These explorations are a good foundation for future studies aimed at highlighting the significance of neurovascular abnormalities, neurovascular remodeling, and angiogenesis in various brain diseases, including neurodegenerative disorders.

\section{Competing interests}

The authors declare that they have no competing interests.

\section{Authors' contributions}

C-CVC, Y-CC, and $\mathrm{H}-\mathrm{YH}$ drafted the manuscript. CC and YC finalized the manuscript. All authors read and approved the final manuscript.

\section{Author details}

'Institute of Biomedical Sciences, Academic Sinica, Taipei 11529, Taiwan.

${ }^{2}$ Institute of Neuroscience, National Yang-Ming University, Taipei 112, Taiwan.

Received: 15 April 2013 Accepted: 17 June 2013

Published: 5 July 2013

\section{References}

1. Stanimirovic DB, Friedman A: Pathophysiology of the neurovascular unit: disease cause or consequence? J Cereb Blood Flow Metab 2012, 32(7):1207-1221.

2. Chow N, Bell RD, Deane R, Streb JW, Chen J, Brooks A, Van Nostrand W, Miano JM, Zlokovic BV: Serum response factor and myocardin mediate arterial hypercontractility and cerebral blood flow dysregulation in Alzheimer's phenotype. Proc Natl Acad Sci U S A 2007, 104(3):823-828.

3. Farkas E, Luiten PG: Cerebral microvascular pathology in aging and Alzheimer's disease. Prog Neurobiol 2001, 64(6):575-611.

4. Kuchibhotla KV, Lattarulo CR, Hyman BT, Bacskai BJ: Synchronous hyperactivity and intercellular calcium waves in astrocytes in Alzheimer mice. Science 2009, 323(5918):1211-1215.

5. Lok J, Gupta P, Guo S, Kim WJ, Whalen MJ, van Leyen K, Lo EH: Cell-cell signaling in the neurovascular unit. Neurochem Res 2007, 32(12):2032-2045.

6. Ongali B, Nicolakakis N, Lecrux C, Aboulkassim T, Rosa-Neto P, Papadopoulos P, Tong XK, Hamel E: Transgenic mice overexpressing APP and transforming growth factor-beta1 feature cognitive and vascular hallmarks of Alzheimer's disease. Am J Pathol 2010, 177(6):3071-3080.

7. Pimentel-Coelho PM, Rivest S: The early contribution of cerebrovascular factors to the pathogenesis of Alzheimer's disease. Eur J Neurosci 2012, 35(12):1917-1937.

8. Kalaria RN: The blood-brain barrier and cerebrovascular pathology in Alzheimer's disease. Ann N Y Acad Sci 1999, 893:113-125.

9. Meyer EP, Ulmann-Schuler A, Staufenbiel M, Krucker T: Altered morphology and $3 \mathrm{D}$ architecture of brain vasculature in a mouse model for Alzheimer's disease. Proc Natl Acad Sci USA 2008, 105(9):3587-3592.

10. Huang YC, Wu YR, Tseng MY, Chen YC, Hsieh SY, Chen CM: Increased prothrombin, apolipoprotein A-IV, and haptoglobin in the cerebrospinal fluid of patients with Huntington's disease. PLoS One 2011, 6(1):e15809.

11. Pan W, Kastin AJ: Adipokines and the blood-brain barrier. Peptides 2007, 28(6):1317-1330.

12. Vis JC, Nicholson LF, Faull RL, Evans WH, Severs NJ, Green CR: Connexin expression in Huntington's diseased human brain. Cell Biol Int 1998, 22(11-12):837-847.

13. Cepeda-Prado E, Popp S, Khan U, Stefanov D, Rodriguez J, Menalled LB, Dow-Edwards D, Small SA, Moreno H: R6/2 Huntington's disease mice develop early and progressive abnormal brain metabolism and seizures. J Neurosci 2012, 32(19):6456-6467.

14. Lucchinetti C, Bruck W, Parisi J, Scheithauer B, Rodriguez M, Lassmann H: Heterogeneity of multiple sclerosis lesions: implications for the pathogenesis of demyelination. Ann Neurol 2000, 47(6):707-717.

15. Brown WR, Thore CR: Review: cerebral microvascular pathology in ageing and neurodegeneration. Neuropathol Appl Neurobiol 2011, 37(1):56-74.

16. Kalaria RN: Vascular basis for brain degeneration: faltering controls and risk factors for dementia. Nutr Rev 2010, 68(Suppl 2):S74-S87.

17. Bell RD, Zlokovic BV: Neurovascular mechanisms and blood-brain barrier disorder in Alzheimer's disease. Acta neuropathologica 2009, 118(1):103-113.

18. Ruitenberg A, den Heijer T, Bakker SL, van Swieten JC, Koudstaal PJ, Hofman A, Breteler MM: Cerebral hypoperfusion and clinical onset of dementia: the Rotterdam Study. Ann Neurol 2005, 57(6):789-794.

19. Chen JJ, Salat DH, Rosas HD: Complex relationships between cerebral blood flow and brain atrophy in early Huntington's disease. Neurolmage 2012, 59(2):1043-1051.

20. Deckel AW, Cohen D: Increased CBF velocity during word fluency in Huntington's disease patients. Prog Neuropsychopharmacol Biol Psychiatry 2000, 24(2):193-206.

21. Deckel AW, Duffy JD: Vasomotor hyporeactivity in the anterior cerebral artery during motor activation in Huntington's disease patients. Brain Res 2000, 872(1-2):258-261.

22. Wolf RC, Gron G, Sambataro F, Vasic N, Wolf ND, Thomann PA, Saft C, Landwehrmeyer GB, Orth M: Magnetic resonance perfusion imaging of resting-state cerebral blood flow in preclinical Huntington's disease. J Cereb Blood Flow Metab 2011, 31(9):1908-1918. 
23. Desai Bradaric B, Patel A, Schneider JA, Carvey PM, Hendey B: Evidence for angiogenesis in Parkinson's disease, incidental Lewy body disease, and progressive supranuclear palsy. J Neural Transm 2012, 119(1):59-71.

24. Desai BS, Schneider JA, Li JL, Carvey PM, Hendey B: Evidence of angiogenic vessels in Alzheimer's disease. J Neural Transm 2009, 116(5):587-597.

25. Holley JE, Newcombe J, Whatmore JL, Gutowski NJ: Increased blood vessel density and endothelial cell proliferation in multiple sclerosis cerebral white matter. Neurosci Lett 2010, 470(1):65-70.

26. Jiang Q, Zhang ZG, Ding GL, Zhang L, Ewing JR, Wang L, Zhang R, Li L, Lu M, Meng H, Arbab AS, Hu J, Li QJ, Pourabdollah Nejad DS, Athiraman H, Chopp M: Investigation of neural progenitor cell induced angiogenesis after embolic stroke in rat using MRI. Neuro Image 2005, 28(3):698-707.

27. Lin CY, Chang C, Cheung WM, Lin MH, Chen JJ, Hsu CY, Chen JH, Lin TN: Dynamic changes in vascular permeability, cerebral blood volume, vascular density, and size after transient focal cerebral ischemia in rats: evaluation with contrast-enhanced magnetic resonance imaging. J Cereb Blood Flow Metab 2008, 28(8):1491-1501.

28. Lin TN, Sun SW, Cheung WM, Li F, Chang C: Dynamic changes in cerebral blood flow and angiogenesis after transient focal cerebral ischemia in rats. Evaluation with serial magnetic resonance imaging. Stroke 2002, 33(12):2985-2991.

29. Seevinck PR, Deddens LH, Dijkhuizen RM: Magnetic resonance imaging of brain angiogenesis after stroke. Angiogenesis 2010, 13(2):101-111.

30. Merrill MJ, Oldfield EH: A reassessment of vascular endothelial growth factor in central nervous system pathology. J Neurosurg 2005, 103(5):853-868.

31. Lagercrantz J, Farnebo F, Larsson C, Tvrdik T, Weber G, Piehl F: A comparative study of the expression patterns for vegf, vegf-b/vrf and vegf-c in the developing and adult mouse. Biochim Biophys Acta 1998, 1398(2):157-163.

32. Stiver SI, Tan X, Brown LF, Hedley-Whyte ET, Dvorak HF: VEGF-A angiogenesis induces a stable neovasculature in adult murine brain. J Neuropathol Exp Neurol 2004, 63(8):841-855.

33. Li Y, Zhang F, Nagai N, Tang Z, Zhang S, Scotney P, Lennartsson J, Zhu C, Qu Y, Fang C, Hua J, Matsuo O, Fong GH, Ding H, Cao Y, Becker KG, Nash A, Heldin CH, Li X: VEGF-B inhibits apoptosis via VEGFR-1-mediated suppression of the expression of $\mathrm{BH} 3$-only protein genes in mice and rats. J Clin Invest 2008, 118(3):913-923.

34. Olsson AK, Dimberg A, Kreuger J, Claesson-Welsh L: VEGF receptor signalling in control of vascular function. Nat Rev Mol Cell Biol 2006, 7(5):359-371.

35. Poesen K, Lambrechts D, Van Damme P, Dhondt J, Bender F, Frank N, Bogaert E, Claes B, Heylen L, Verheyen A, Raes K, Tjwa M, Eriksson U, Shibuya M, Nuydens R, Van Den Bosch L, Meert T, D'Hooge R, Sendtner M, Robberecht W, Carmeliet P: Novel role for vascular endothelial growth factor (VEGF) receptor-1 and its ligand VEGF-B in motor neuron degeneration. J Neurosci 2008, 28(42):10451-10459.

36. Harper SJ, Bates DO: VEGF-A splicing: the key to anti-angiogenic therapeutics? Nat Rev Cancer 2008, 8(11):880-887.

37. Neufeld G, Cohen T, Gengrinovitch S, Poltorak Z: Vascular endothelial growth factor (VEGF) and its receptors. FASEB J 1999, 13(1):9-22.

38. Ohtaki H, Fujimoto T, Sato T, Kishimoto K, Fujimoto M, Moriya M, Shioda S: Progressive expression of vascular endothelial growth factor (VEGF) and angiogenesis after chronic ischemic hypoperfusion in rat. Acta Neurochir Suppl 2006, 96:283-287.

39. Krum JM, Mani N, Rosenstein JM: Roles of the endogenous VEGF receptors flt- 1 and flk-1 in astroglial and vascular remodeling after brain injury. Exp Neurol 2008, 212(1):108-117.

40. Holmes K, Roberts OL, Thomas AM, Cross MJ: Vascular endothelial growth factor receptor-2: structure, function, intracellular signalling and therapeutic inhibition. Cell Signal 2007, 19(10):2003-2012.

41. Rosenstein JM, Krum JM: New roles for VEGF in nervous tissue-beyond blood vessels. Exp Neurol 2004, 187(2):246-253.

42. Krum JM, Mani N, Rosenstein JM: Angiogenic and astroglial responses to vascular endothelial growth factor administration in adult rat brain. Neuroscience 2002, 110(4):589-604.

43. Lennmyr F, Ata KA, Funa K, Olsson Y, Terent A: Expression of vascular endothelial growth factor (VEGF) and its receptors (Flt-1 and Flk-1) following permanent and transient occlusion of the middle cerebral artery in the rat. J Neuropathol Exp Neurol 1998, 57(9):874-882.

44. Ogunshola OO, Stewart WB, Mihalcik V, Solli T, Madri JA, Ment LR: Neuronal VEGF expression correlates with angiogenesis in postnatal developing rat brain. Brain Res Dev Brain Res 2000, 119(1):139-153.
45. Stewart PA, Isaacs H, LaManna JC, Harik SI: Ultrastructural concomitants of hypoxia-induced angiogenesis. Acta Neuropathol 1997, 93(6):579-584.

46. Xiang F, Tanaka J, Takahashi J, Fukuda T: Expression of vascular endothelial growth factor (VEGF) and its two receptors in diffusely infiltrating astrocytomas and relationship to proliferative activity of tumor cells. Brain Tumor Pathol 2001, 18(2):67-71.

47. Argaw AT, Asp L, Zhang J, Navrazhina K, Pham T, Mariani JN, Mahase S, Dutta DJ, Seto J, Kramer EG, Ferrara N, Sofroniew MV, John GR: Astrocytederived VEGF-A drives blood-brain barrier disruption in CNS inflammatory disease. J Clin Invest 2012, 122(7):2454-2468.

48. Croll SD, Ransohoff RM, Cai N, Zhang Q, Martin FJ, Wei T, Kasselman LJ, Kintner J, Murphy AJ, Yancopoulos GD, Wiegand SJ: VEGF-mediated inflammation precedes angiogenesis in adult brain. Exp Neurol 2004, 187(2):388-402.

49. Ballard C, Gauthier S, Corbett A, Brayne C, Aarsland D, Jones E: Alzheimer's disease. Lancet 2011, 377(9770):1019-1031.

50. Chiarini A, Whitfield J, Bonafini C, Chakravarthy B, Armato U, Dal Pra I: Amyloid-beta(25-35), an amyloid-beta(1-42) surrogate, and proinflammatory cytokines stimulate VEGF-A secretion by cultured, early passage, normoxic adult human cerebral astrocytes. J Alzheimers Dis 2010, 21(3):915-926.

51. Jantaratnotai N, Ryu JK, Schwab C, McGeer PL, McLarnon JG: Comparison of Vascular Perturbations in an Abeta-Injected Animal Model and in AD Brain. Int J Alzheimers Dis 2011, 2011:918280.

52. Ryu JK, Cho T, Choi HB, Wang YT, MCLarnon JG: Microglial VEGF receptor response is an integral chemotactic component in Alzheimer's disease pathology. J Neurosci 2009, 29(1):3-13.

53. Ryu JK, McLarnon JG: A leaky blood-brain barrier, fibrinogen infiltration and microglial reactivity in inflamed Alzheimer's disease brain. J Cell Mol Med 2009, 13(9A):2911-2925.

54. Biron KE, Dickstein DL, Gopaul R, Jefferies WA: Amyloid triggers extensive cerebral angiogenesis causing blood brain barrier permeability and hypervascularity in Alzheimer's disease. PLoS One 2011, 6(8):e23789.

55. Wada K, Arai H, Takanashi M, Fukae J, Oizumi H, Yasuda T, Mizuno Y, Mochizuki $\mathrm{H}$ : Expression levels of vascular endothelial growth factor and its receptors in Parkinson's disease. Neuroreport 2006, 17(7):705-709.

56. Barcia C, Bautista V, Sanchez-Bahillo A, Fernandez-Villalba E, Faucheux B, Poza y Poza M, Fernandez Barreiro A, Hirsch EC, Herrero MT: Changes in vascularization in substantia nigra pars compacta of monkeys rendered parkinsonian. J Neural Transm 2005, 112(9):1237-1248.

57. Barcia C, Emborg ME, Hirsch EC, Herrero MT: Blood vessels and parkinsonism. Front Biosci 2004, 9:277-282.

58. Lindgren HS, Ohlin KE, Cenci MA: Differential involvement of D1 and D2 dopamine receptors in L-DOPA-induced angiogenic activity in a rat model of Parkinson's disease. Neuropsychopharmacology 2009, 34(12):2477-2488.

59. Ohlin KE, Francardo V, Lindgren HS, Sillivan SE, O'Sullivan SS, Luksik AS, Vassoler FM, Lees AJ, Konradi C, Cenci MA: Vascular endothelial growth factor is upregulated by L-dopa in the parkinsonian brain: implications for the development of dyskinesia. Brain 2011, 134(Pt 8):2339-2357.

60. Ezaki T, Baluk P, Thurston G, La Barbara A, Woo C, McDonald DM: Time course of endothelial cell proliferation and microvascular remodeling in chronic inflammation. Am J Pathol 2001, 158(6):2043-2055

61. Fioravanzo L, Venturini M, Di Liddo R, Marchi F, Grandi C, Parnigotto PP, Folin M: Involvement of rat hippocampal astrocytes in beta-amyloid-induced angiogenesis and neuroinflammation. Curr Alzheimer Res 2010, 7(7):591-601.

62. Grammas P, Sanchez A, Tripathy D, Luo E, Martinez J: Vascular signaling abnormalities in Alzheimer disease. Cleve Clin J Med 2011, 78(Suppl 1):S50-S53.

63. Nicolakakis N, Aboulkassim T, Aliaga A, Tong XK, Rosa-Neto P, Hamel E: Intact memory in TGF-beta1 transgenic mice featuring chronic cerebrovascular deficit: recovery with pioglitazone. J Cereb Blood Flow Metab 2011, 31(1):200-211.

64. Argaw AT, Zhang Y, Snyder BJ, Zhao ML, Kopp N, Lee SC, Raine CS, Brosnan CF, John GR: IL-1beta regulates blood-brain barrier permeability via reactivation of the hypoxia-angiogenesis program. J Immunol 2006, 177(8):5574-5584.

65. Imhof BA, Aurrand-Lions M: Angiogenesis and inflammation face off. Nat Med 2006, 12(2):171-172.

66. Ryu JK, McLarnon JG: Thalidomide inhibition of perturbed vasculature and glial-derived tumor necrosis factor-alpha in an animal model of inflamed Alzheimer's disease brain. Neurobiol Dis 2008, 29(2):254-266.

67. Franciosi S, Ryu JK, Shim Y, Hill A, Connolly C, Hayden MR, McLarnon JG, Leavitt BR: Age-dependent neurovascular abnormalities and altered 
microglial morphology in the YAC128 mouse model of Huntington disease. Neurobiol Dis 2012, 45(1):438-449.

68. Niwa K, Kazama K, Younkin L, Younkin SG, Carlson GA, ladecola C: Cerebrovascular autoregulation is profoundly impaired in mice overexpressing amyloid precursor protein. Am J Physiol Heart Circ Physiol 2002, 283(1):H315-H323.

69. Paris D, Patel N, DelleDonne A, Quadros A, Smeed R, Mullan M: Impaired angiogenesis in a transgenic mouse model of cerebral amyloidosis. Neurosci Lett 2004, 366(1):80-85.

70. Barbier EL, Lamalle L, Decorps M: Methodology of brain perfusion imaging. J Magn Reson Imaging 2001, 13(4):496-520.

71. Huisman TA, Sorensen AG: Perfusion-weighted magnetic resonance imaging of the brain: techniques and application in children. Eur Radiol 2004, 14(1):59-72.

72. Oostendorp M, Post MJ, Backes WH: Vessel growth and function: depiction with contrast-enhanced MR imaging. Radiology 2009, 251 (2):317-335.

73. Reichenbach JR, Venkatesan R, Schillinger DJ, Kido DK, Haacke EM: Small vessels in the human brain: MR venography with deoxyhemoglobin as an intrinsic contrast agent. Radiology 1997, 204(1):272-277.

74. Tropres I, Grimault S, Vaeth A, Grillon E, Julien C, Payen JF, Lamalle L, Decorps M: Vessel size imaging. Magn Reson Med 2001, 45(3):397-408.

75. Tofts PS: Modeling tracer kinetics in dynamic Gd-DTPA MR imaging. J Magn Reson Imaging 1997, 7(1):91-101.

76. Fisel CR, Ackerman JL, Buxton RB, Garrido L, Belliveau JW, Rosen BR, Brady TJ: MR contrast due to microscopically heterogeneous magnetic susceptibility: numerical simulations and applications to cerebral physiology. Magn Reson Med 1991, 17(2):336-347.

77. Weisskoff RM, Zuo CS, Boxerman JL, Rosen BR: Microscopic susceptibility variation and transverse relaxation: theory and experiment. Magn Reson Med 1994, 31(6):601-610.

78. Zaharchuk G: Theoretical basis of hemodynamic MR imaging techniques to measure cerebral blood volume, cerebral blood flow, and permeability. AJNR Am J Neuroradiol 2007, 28(10):1850-1858.

79. Lin CY, Lin MH, Cheung WM, Lin TN, Chen JH, Chang C: In vivo cerebromicrovasculatural visualization using 3D DeltaR2-based microscopy of magnetic resonance angiography (3DDeltaR2-mMRA). Neurolmage 2009, 45(3):824-831.

80. Yanev P, Dijkhuizen RM: In vivo imaging of neurovascular remodeling after stroke. Stroke 2012, 43(12):3436-3441.

81. Malpass K: Alzheimer disease: Arterial spin-labeled MRI for diagnosis and monitoring of AD. Nature reviews. Neurology 2012, 8(1):3.

82. Chen W, Song X, Beyea S, D'Arcy R, Zhang Y, Rockwood K: Advances in perfusion magnetic resonance imaging in Alzheimer's disease. Alzheimers Dement 2011, 7(2):185-196.

83. Austin BP, Nair VA, Meier TB, Xu G, Rowley HA, Carlsson CM, Johnson SC, Prabhakaran V: Effects of hypoperfusion in Alzheimer's disease. J Alzheimers Dis 2011, 26(Suppl 3):123-133.

84. Binnewijzend MA, Kuijer JP, Benedictus MR, van der Flier WM, Wink AM, Wattjes MP, van Berckel BN, Scheltens P, Barkhof F: Cerebral blood flow measured with 3D Pseudocontinuous arterial spin-labeling MR imaging in Alzheimer disease and mild cognitive impairment: a marker for disease severity. Radiology 2013, 267(1):221-230.

85. Kim SM, Kim MJ, Rhee HY, Ryu CW, Kim EJ, Petersen ET, Jahng GH: Regional cerebral perfusion in patients with Alzheimer's disease and mild cognitive impairment: effect of APOE epsilon4 allele. Neuroradiology 2013, 55(1):25-34

86. Mak HK, Chan Q, Zhang Z, Petersen ET, Qiu D, Zhang L, Yau KK, Chu LW, Golay X: Quantitative assessment of cerebral hemodynamic parameters by QUASAR arterial spin labeling in Alzheimer's disease and cognitively normal Elderly adults at 3-tesla. J Alzheimers Dis 2012, 31(1):33-44.

87. Kara F, Dongen ES, Schliebs R, Buchem MA, Groot HJ, Alia A: Monitoring blood flow alterations in the Tg2576 mouse model of Alzheimer's disease by in vivo magnetic resonance angiography at $17.6 \mathrm{~T}$. Neurolmage 2012, 60(2):958-966.

88. Wang H, Golob EJ, Su MY: Vascular volume and blood-brain barrier permeability measured by dynamic contrast enhanced MRI in hippocampus and cerebellum of patients with $\mathrm{MCl}$ and normal controls. J Magn Reson Imaging 2006, 24(3):695-700.

89. Anderson VC, Lenar DP, Quinn JF, Rooney WD: The blood-brain barrier and microvascular water exchange in Alzheimer's disease. Cardiovasc Psychiatry Neurol 2011, 2011:615829.
90. Brusa L, Bassi A, Pierantozzi M, Gaudiello SFF, Floris R, Stanzione P: Perfusion-weighted dynamic susceptibility (DSC) MRI: basal ganglia hemodynamic changes after apomorphine in Parkinson's disease. Neurol Sci 2002, 23(Suppl 2):S61-S62.

91. Melzer TR, Watts R, MacAskill MR, Pearson JF, Rueger S, Pitcher TL, Livingston L, Graham C, Keenan R, Shankaranarayanan A, Alsop DC, Dalrymple-Alford JC, Anderson TJ: Arterial spin labelling reveals an abnormal cerebral perfusion pattern in Parkinson's disease. Brain 2011, 134(Pt 3):845-855.

92. Choi JK, Chen YI, Hamel E, Jenkins BG: Brain hemodynamic changes mediated by dopamine receptors: role of the cerebral microvasculature in dopamine-mediated neurovascular coupling. Neurolmage 2006, 30(3):700-712

93. Chen CC, Shih YY, Chang C: Dopaminergic imaging of nonmotor manifestations in a rat model of Parkinson's disease by fMRI. Neurobiol Dis 2012, 49C:99-106.

doi:10.1186/1423-0127-20-47

Cite this article as: Chen et al:: Neurovascular abnormalities in brain disorders: highlights with angiogenesis and magnetic resonance imaging studies. Journal of Biomedical Science 2013 20:47.

\section{Submit your next manuscript to BioMed Central and take full advantage of:}

- Convenient online submission

- Thorough peer review

- No space constraints or color figure charges

- Immediate publication on acceptance

- Inclusion in PubMed, CAS, Scopus and Google Scholar

- Research which is freely available for redistribution 